\title{
Caravaggio's cinematic painting: Fictionalising art and biography in the artist biopic
}

\author{
KEELEY SAUNDERS, University of Kent
}

\section{ABSTRACT}

Explorations of the artist in the biopic genre are often formulaic in approach. The biographical narrative, modelled on the literary monograph, celebrates a public figure who overcomes challenges to rise to the top of their field. These films traditionally present the artist's life and work as intrinsically involved with each other so that the artwork can only be explained through contextualising biographical knowledge. Derek Jarman's Caravaggio (1986), in the vein of his highly personal, experimental filmmaking, is not a biopic in this traditional sense. Taking advantage of what little is known about Michelangelo Merisi da Caravaggio, the Italian painter widely recognised as the first great artist of the Baroque period and a master of chiaroscuro, Jarman constructs a heavily fictional 'biographical' narrative. This narrative is built upon historical speculation, personal identification, and most significantly, his subjective interpretation and visualisation of the paintings themselves.

A series of tableaux vivants, delicately postured, almost still, recreations of the paintings, provide the narrative impetus in Caravaggio. Many of these are situated as poses in preparation for Caravaggio's painting. These recreations are removed from their historical context, disregarding the artworks' chronology and misplacing characters and events to construct a part-Jarman/part-Caravaggio profile - fictionalising both art and biography. This paper explores Jarman's intricate appropriation of the art and biography of the artist in Caravaggio, and how this is implemented, and complicated, to serve his own narrative agenda. Developing André Bazin's discussion about the adoption of one medium into another in 'Painting and Cinema,' I analyse the tableaux representing The Martyrdom of Saint Matthew (1599-1600), The Entombment of Christ (1602-03), and Death of the Virgin (1606). This analysis takes place on three levels: firstly, art-history 'fidelity;' secondly, the perversion of the self-portrait; and finally, with direct reference to Bazin's essay, the editing of the art-image.

\section{KEYWORDS}

Derek Jarman, Caravaggio, biopic, art in film, tableau vivant, biography, painting and cinema

\section{Introduction: Film, art and biography}

Filmmakers and other artists often explore their chosen medium's capacity for adoption, quotation and homage within their work. The use of painting in film, for example, whether it is categorised 'art in film,' 'painting in cinema,' or any other term, is a notable example of this, with filmmakers appropriating other artists' work, weaving influences and references into their own projects. This process is sometimes explicit and at other times obscure, can be conscious or subconscious, and acknowledged or not. This article will address the 
relationship between painting and cinema, bringing the often disparate academic worlds of art history and film studies together to discuss how painting can be displayed in film through what I have labelled the 'art-image'. The 'art-image' is a sort of tableau vivant: the physical recreation, or envisioning, of a still painting in a motion picture. I will explore the function of these 'art-images' in the construction of a cinematic biographical narrative, considering the relationship between director, painter and the art. I will examine the process of appropriation by the filmmaker, and analyse how the biopic of an artist presents the subject's 'art-images', how these images are situated within the narrative, and how these relate to the biography of the artist.

Derek Jarman's Caravaggio (1986) is critically acknowledged for its celebration of art and the figure of the artist. It is also noteworthy for its creative exploration of generic boundaries of the biopic and the relationship between painting and cinema. The film, about Michelangelo Merisi da Caravaggio (1573-1610), an Italian painter widely recognised as the first great artist of the Baroque period and a master of chiaroscuro, was originally intended as a development for the Italian director, Pier Paolo Pasolini. The original project was unfortunately disbanded due to Pasolini's murder in 1975. Following Pasolini's death, art dealer and producer of the film, Nicolas Ward-Jackson, approached British avant-garde filmmaker, Jarman, with the proposition of making a film about the artist. Jarman accepted and began work on the deeply personal project, which would span several years of his career. Historically, little is known about Caravaggio's life. He was born in northern Italy in 1573 and worked in Rome, Naples, Malta and Sicily. Infamous in Rome for his brawling and frequently in trouble with the police, in 1606 Caravaggio kills a man (possibly accidentally), and flees the city to a small Italian beach village, Porto Ercole, where he dies four years later. Jarman plays with the lack of knowledge about the painter's life in Caravaggio: narratively framing the film through the complex love affair between 'Michele' Caravaggio and two of his models, telling a heavily fictionalised story of the painter's life, and postulating how many of his most famous artworks came to light

In the film, Caravaggio's artworks are not just represented or simply recorded, but rather physically recreated. They palpably and three-dimensionally exist within the verisimilitude of the filmic world. As such, they present the complex visualisation of the artists' paintings as inherently involved with the artists' reality. The construction of the artworks in the film allows us to acknowledge the presence of both the media of painting and of film, drawing attention to their status as paintings reworked by film, and presenting the issues that lie within this delicate relationship. Moreover, Caravaggio does not just recreate the paintings through their new adopted medium, but relocates them. This relocation can be understood in terms of medium specificity ${ }^{1}$, certainly, but knowledge of the biopic genre can also enlighten this historical displacement of the artworks. Here we can explore the biography of the painter and focus on the relationship between the artist, his biography, and specific paintings. In Caravaggio, Jarman removes the paintings from their historical context, purposely disregarding their original chronology and misplacing characters and events to serve his own narrative agenda and construct his part-Jarman/part-Caravaggio profile. In effect, Jarman fictionalises both art and biography. 


\section{The artist biopic}

In her exploration of the multiple films made about the life and art of Mexican painter, Frida Kahlo, at the turn of the millennium, 'Life as Art/Art as Life: Dramatizing the Life and Work of Frida Kahlo,' Tina Olsin Lent addresses many issues that relate to Caravaggio. Julie Taymor's feature, Frida (2002), provides the primary focus of the article. Lent, through her discussion of the convention-driven biopic genre, demonstrates Frida's awareness of, and adherence to, generic conventions, and its originality in presenting Kahlo's art as an integral visual component of her life. Lent outlines the role of the artist's monograph and biographies following monographic conventions in the construction of a standard biopic. Presenting the artist's life and their work as intrinsically involved with each other so that the paintings 'can be explained only through biography' (2007: 70), monographs direct their interest towards the artistic ideal of a genius figure battling with his inner demons. This is the image of a tortured soul with an unfortunate upbringing who finds release from depression or addiction through his expression in art. ${ }^{2}$ This structure developed the primary approach of the biopic, not just artist specific, but genre wide: celebrating a public figure that overcomes challenges to rise to the top of their field.

Lent suggests that Frida's use of tableaux vivants, literally bringing Kahlo's paintings alive, supplements the biographical approach of the film and acts as a 'literal and intuitive transcription of [Kahlo's] lived reality' (2007: 74). The recreations of Kahlo's paintings, with Salma Hayek placed as Kahlo the painter and the subject, are successful because Kahlo's work is associated with recognition of her biography (it is difficult not to equate the two). Although, as Lent justifiably comments, '[n]ever does Taymor go beyond the most literal use of Kahlo's work, and never is Kahlo credited with the intellectual, innovative, creative, symbolic, or interpretive work that constitutes art practice' (2007: 74). Caravaggio breaks from what is presented to us in Frida: displaying the creativity of the painter which Lent feels is lacking from her case study by literally presenting the 'art practice' as paramount to the painter. This is established by the presence of the tableaux in the studio, demonstrating an alternative relationship between the artworks and the biographical narrative. With a few exceptions, most notably the final sequence of Caravaggio as Christ in The Entombment of Christ (1602-03), the paintings are present in the artist's world as poses waiting to be painted, situating the act of painting as essential to our understanding of Caravaggio the man and artist. Additionally, the lack of historical knowledge about Caravaggio's life gives Jarman the opportunity to postulate a narrative between this 'character' and these paintings he created. This ahistorical mediation of biography and art encourages reflection on art-history 'fidelity' in the artist biopic film.

With the tableau vivant in mind, Frida does treat art in the biopic with a similar deliberation as can be seen in Caravaggio: as an external vision beyond the image on a canvas. Related to this is the observation that many of Kahlo's paintings represented in the film are examples of her extensive exploration within self-portraiture. Indeed, many of Kahlo's most famous paintings are deeply personal self-portraits with the artist placing herself, her suffering, and personal tragedies (such as the trolley accident which crippled her and lead to her miscarriages) as the main subject. Taymor frames the film's narrative around the significance 
of this trolley accident and her troubled relationship with her husband, painter Diego Rivera. In doing this, Taymor builds upon the designated moments of important personal history displayed in Kahlo's work (even if the paintings' position within the filmic narrative is occasionally factually questionable). ${ }^{3}$ Similarly, in Caravaggio, as we shall discuss later, Jarman draws from Caravaggio's own prominent self-portraits, but uses his self-appointed freedom with the artist's oeuvre and the ongoing academic ambiguity about the status of many reputed self-portraits to his advantage, exploring the potential of his subjective interpretation within the constructed biography and narrative of the film.

Lent's interest in the role taken and decisions made by Julie Taymor during the production process of Frida neatly develops Andre Bazin's thoughts on the role of the filmmaker in revisioning art in film, as defined in his short article entitled 'Painting and Cinema.' Here Bazin is interested in the adoption of one medium into another, the transference of painting into film, and the relationship between the two in this new position. He states that a film about paintings, or one that displays paintings, can never truly do justice to the artworks because of the intrinsically different aesthetic qualities of the media. As he states,

Not only is the film a betrayal of the painter, it is also a betrayal of the painting and for this reason: the viewer, believing that he is seeing the picture as painted, is actually looking at it through the instrumentality of an art form that profoundly changes its nature. (2004: 165)

He begins this assessment by briefly delineating the filmmaker as the cause of the problem, outlining that it is their decisions that misplace the artworks 'in time and spirit' (164), forging narrativised relationships between paintings that do not exist. Caravaggio does not directly feature artworks in the way that Bazin discusses. Bazin references Alain Resnais' Van Gogh (1948) as an example of a film which records the image of actual paintings and presents it as a filmed record, displaying the image of a painting as the original painting, not replicated or remade by the filmmaker. Caravaggio's use of tableaux vivants is clearly not such an example of paintings being recorded by film. ${ }^{4}$ Nevertheless, these original three-dimensional art-image recreations are still subject to, and examples of, the difference in the media. He then develops his argument, defining the revision of time and space within the two media.

The initial acknowledgment of the filmmaker as a figure that reorganises the paintings into new relationships is always applicable; Caravaggio demonstrates a narrative formed by Derek Jarman's interpretive and arguably highly personal readings of the artist's paintings. This directorial authority is emphasised further given the film's generic foundation and the integral role that the paintings are given in our understanding of the artist. The view that the filmmaker, consciously or otherwise, prioritises his intentions above the artist's original aims, highlights a concern with narrative, particularly biographical, that points to mediumspecificity (the 'spirit' of the artwork (164)). Bazin's discussion of time presents his summary of the sequential structure of film ('geographical') in opposition to the still depth of painting ('geological' (2004: 165)). This observation pre-empts John A. Walker's statement that '[an] oil painting is a silent, still, atemporal, handmade, unique object; [...] whereas the cinema's and television's images are accompanied by sounds and music; they are moving, multiple, 
temporal' (1993: 7). In Caravaggio this is particularised with the vision of the literal movement of the recreated 'paintings', which come alive with actors performing their roles as the figures in the paintings, and are physically part of the artist's universe.

Finally, the role of the frame provides the focus for Bazin's discussion of space. He states that the frame of a painting has more importance than that which is simply decorative or rhetorical; rather that it serves as a boundary between the painting and reality, marking the distinction between the world and a representation of that world. The edges of a screen, however, are not to be considered a 'frame', and the film image, as consequence, is just a highlighted part of our existence with the edges 'of a piece of masking that shows only a portion of reality' (2004: 166). This argument naturally stems from the ontological assessment that celluloid film records and presents reality. ${ }^{5}$ A film can be constructed; with actors playing characters, sets created with props arranged, with a selection of shots and edits; but the event recorded, although it may not have been authentic, still existed in reality. Even if the frame (in the cinematographic understanding of the word, not as a 'picture-frame') only highlights a specific section available for viewing, this world exists and continues beyond the camera. The image actually occurred, tangibly, within our reality and was captured as such.

Painting, however, is an image intrinsically created and composed, displaying only what has been envisioned within the frame, and is duly unable to directly record reality. Thus, Bazin states that painting 'takes on the spatial properties of cinema and becomes part of that "picturable" world that lies beyond it on all sides' (2004: 166). This posits that in its transference from wall to screen, painting, in the process of losing its frame, also loses its properties belonging to painting as a medium and becomes part of the boundless world that exists beyond the screen. This is visualised literally in Caravaggio by the three-dimensional images that replace and bring the artworks to life. The fram(e)ing of the paintings is also a valid exploration, with the film visualising this issue of space through its insistence in editing the art-image. The tableaux are frequently broken up by Jarman. They are presented in small focal shots highlighting sections from the main image, challenging the intended viewing space of the original painting and deliberately forcing a narrative within the 'still' image upon the audience.

\section{Caravaggio: The master of chiaroscuro}

Beginning with the painter lying on his deathbed in Porto Ercole, Caravaggio journeys through his life and career via extended flashback. The narrative is led by the love triangle between Michele Caravaggio, Ranuccio (a street-fighter), and Lena (Ranuccio's lover), and their developed role as Caravaggio's models: the subjects for his paintings and the film's tableaux. The sequences in the film featuring Caravaggio's work can be named as tableau vivant without any dispute over the term: they are delicately postured living - almost still recreations of the paintings. The majority of scenes that feature these tableaux, as formerly mentioned, are set in Caravaggio's studio as he is working on a painting. This is facilitated by their placement within the film's narrative as poses in preparation for Caravaggio's painting. In many cases we are shown the model in the pose and the canvas that the painter is working on, or one that has been completed (as can be seen in the scene featuring Amor Vincit Omnia 
[Love Victorious] (1601-02)). These set-ups, or tableaux, look like the paintings because they are the source material that Caravaggio is painting from: the light that is celebrated in Caravaggio's paintings was created, as Jarman visually suggests, from the natural light of the room he worked within.

In 'The Suspended Spectacle of History' (2003), a comprehensive analysis of the tableaux of Caravaggio, James Tweedie explores how Jarman manipulates historical fact and interprets paintings to create his own image of Caravaggio: a fictional biographical account of Caravaggio's life filtered through Jarman himself. Tweedie works through Jarman's personal readings and experiences and provides examples of this personalisation most clearly demonstrated through the film. Of the historical accuracy of the tableaux he posits:

the tableau vivant exists in several tenses at once - in the present of the performance, in the past viewed though historical representation, and in the future perfect, through which characters overlap with the paintings and historical figures that will have been. (2003: 391)

For example, Ranuccio is believed to be loosely based on Ranuccio Tomassoni, the young man that Caravaggio killed in 1606. Although this murder occurs in the film, it is very doubtful that the event happened in the same situation ${ }^{6}$, and he certainly was not the model for the paintings that Jarman places him in. Equally, Lena was historically one of Caravaggio's favourite models: a prostitute known as 'Caravaggio's girl,' who was the pregnant model for Death of the Virgin (1606), which Jarman replicates, but who was not recognised as the model for the other paintings reimagined in the film. In a close biographical examination of the film it is clear that Jarman has taken liberties with the artist's history, drawing from his readings of the paintings: as openly exclaimed in his statement that if [the narrative] is fiction, it is the fiction of the paintings' (Jarman, 1986: 75).

Throughout his handwritten notes in his personal production diaries Jarman accounts his interest in Caravaggio's work and his intentions with the paintings which, through the many drafts, were always planned as a major part of the film. 'A breakdown of the paintings' (Derek Jarman collection, BFI Special Collections Department, box 6) outlines the initial stages of selection, naming the paintings of interest to his project. 'Notes on leading players' (Derek Jarman collection, box 6) demonstrates his method of characterisation: visualising the main characters of the film through Caravaggio's paintings. Unsurprisingly, the character of Caravaggio is illustrated with an image of one of Caravaggio's known self-portraits: his turned head in the background of The Martyrdom of Saint Matthew (1599-1600).

Additionally, Lena is pictured as Judith Beheading Holofernes (1598), and as adapted to the film, Ranuccio is John the Baptist (1604), and Del Monte is Saint Jerome (1605-06). As Leo Bersani \& Ulysses Dutoit conclude in their monograph on the film:

[The] sense of the paintings' power is so acute that [Jarman] not only imagines them to have 'instigated' a life but is also compelled partially to 'correct' the paintings so that their effect on the painter's life may be retroactively included within them. (1999: 67) 
Jarman's narrative is based on a combination of real people and, as described above, the visual 'characterisation' of the paintings, set in predominately fictional events and other acts based around painting: be it the unveiling party of Love Victorious, or the process of work as seen in the sequence of The Martyrdom of Saint Matthew. Caravaggio is almost entirely constructed around the original paintings, and the art-image sequences in the film undoubtedly signify their integral role within the assembly of the narrative. The collection of sequences building up to and including the painting of The Martyrdom of Saint Matthew, for example, provide an excellent illustration of a narrative-forming tableau, presenting a multitude of contexts, and tenses (as Tweedie suggests), in which the painting is present.

\section{The Martyrdom of Saint Matthew: Art history 'fidelity'}

In the film, sat in a bar with his friend, Davide, Caravaggio discusses the disastrous work on The Martyrdom, exclaiming that "Saint Matthew himself couldn't save it". This scene marks the first time Michele notices Ranuccio, who is sat across at another table; a fortuitous encounter given the topic of discussion between the friends and the future role the fighter will play in the painter's art. In the next scene, set in his studio, Caravaggio continues work on the yet unseen easel in front of the Cardinal Del Monte (a historical patron of Caravaggio's work), pacing up and down in front of a group of models posing for what can be understood as one of the original poses for The Martyrdom.

Rowland Wymer (2005), in his book on Jarman's feature films, notes how x-rays of the original painting uncovered the difficulties Caravaggio had creating the commission: revealing two other versions of the image that had been painted over, completely rearranging the composition and character positioning during the process. In fact, it is clear from the $\mathrm{x}$ ray photographs available that Jarman's opening Martyrdom sequence is inspired by Caravaggio's initial attempts at portraying the event. The figures situated on the left-hand side of the frame are positioned differently and the spacing between the figures is far wider in the tableau, but the executioner wearing the helmet and the two right-hand characters' positions and poses replicate the details of the initial image, as exhibited in the old man's vestment-like attire and the young boy's outstretched arm. An edit even isolates the two figures on the right in a medium close-up, signifying their importance within the composition (other shots soon follow, but it is significant that this section of the tableau is selected first). Unusually for the film we do not witness Caravaggio in the act of painting, which many other scenes delight in displaying. Instead we sense the difficulty he is having: we watch him deep in thought, evaluating possibilities, and, when he does finally pick up his brush, we see him disturbed by the laughing Cardinal and his awakened models.

The next scene shows Caravaggio standing in front of his unfinished painting (a replica painted by production designer, Christopher Hobbs). As the camera pulls back to a mediumlong shot, the canvas engulfs him, dwarfing his body against a sea of red pigment, allowing the viewer to gauge just how expansive the project is and empathise with the difficulty he is experiencing. In this short amount of screen time we have been introduced to an abundance of information which borders between historical fact and interpretive fiction, with 'characters overlap[ping] with the paintings and historical figures' (Tweedie, 2003: 391). This includes 
the fictional introduction of characters, Davide and Ranuccio; the narrative representation of historical characters (Caravaggio, Cardinal del Monte and Ranuccio) and the painting (the factual commission and previous versions alongside the potentially fictional circumstances); the visual representation of the painting through tableaux and unfinished canvas recreations; and an suggested insight into Caravaggio's working methods and the life of an artist of the early 1600s in Italy. The fight sequence between Ranuccio and Davide may actually act as a further scene linked to the painting, demonstrating the source of Caravaggio's inspiration. Although not explicit, there are two shots, when Davide is beaten and Ranuccio is holding his head and looking down at him just before he deals the final blow, which connote the look of Saint Matthew looking down at his victim in Caravaggio's painting. The painter's fascinated attention and eager work in the next scene suggests that he may have replicated this look in the painting with that specific moment in mind.

Finally, after meeting (or perhaps the term 'buying' would be more appropriate) Ranuccio at his winning fight, we are shown the real tableau vivant, with this new model as the executioner. Caravaggio sets his model in the pose he requires, mirroring the amended partpainted canvas we can see in the background. Many of the following shots show multiple elements of the process; Ranuccio posing with a sword in the left foreground, and Caravaggio painting on the large canvas at the back centre-right, with his work table covered in paints, mixing bowls and instruments. The tableau image itself perfectly illustrates the work-inprogress, with Ranuccio standing alone, a single figure against darkness for the painter to focus his attention on. The scene communicates the narrative importance this process has had. After a quick succession of shots between the payment of gold coins, close-ups of brush on canvas, and swift pose rearrangements, connoting the speed at which the inspired painter has worked, Caravaggio places a gold coin in his mouth, from which Ranuccio intimately bites from him. Their relationship has formed and the construction of the act of painting has allowed the characters to further their involvement, intimately and narratively, with each other.

This connection is extended in the final The Martyrdom reference, a standalone scene that bares no pivotal role in narrative construction but forms an important demonstration of the successful combination of painting, art-image and narrative suggestion. Opening at the end of Caravaggio's voiceover reading of the 'Song of Songs' book from the Old Testament, the film returns to the unfinished canvas of the painting, slowly pulling-back to reveal Ranuccio in his executioner pose standing in front of the image. As the camera moves back further we become aware of the figure of Caravaggio looming in the background on the left-hand side of the canvas. Although it is unclear what his expression is connoting, Caravaggio's reading from 'Song of Songs' - "I sought him but found him not" - is presumably a reference to his emerging love for Ranuccio, as the latter character appears in the frame just as this phrase is uttered. The painter closes his heavy overcoat and turns his head just slightly towards Ranuccio to directly evoke the positioning and solemn expression of Caravaggio's own selfportrait in the original painting. In that single gesture he joins Ranuccio in the present parttableau, but also becomes part of the future painting, stood against the uncompleted canvas, pre-empting his self-illustrated appearance that is yet to be created. 
Furthermore, as Tweedie acknowledges:

Jarman's film disrupts and dismembers the paintings included in the film, as it attempts to renovate these now well-known and widely circulated images through a directed tour of the canvas and the uniquely cinematic project used to reveal their submerged autobiography [of Jarman himself]. (2003: 397)

The painting has already announced itself as personally important to the director; it has been selected for presentation as three tableaux vivants in various forms and, as outlined above, is a significant point within the narrative structure, interweaving character introductions and the work of the artist. Significantly, Jarman famously announced his interpretation of the artist's self-portrait in The Martrydom as 'a look that no one can understand unless he has stood till 5 a.m. in a gay bar hoping to be fucked' (Jarman, 1984: 22). This quote exemplifies Jarman's interpretative methodology - reading his life into the situations of the paintings. Presumably, he can understand this 'look' because he himself has been in that situation. Jarman recognises himself in the face of the artist and strives to represent this in his visual translation of the paintings.

\section{Self-portraits and The Entombment of Christ}

This narrative 'manipulation' is continued and extended in the other created self-portraits in Caravaggio. Unlike The Martyrdom, however, these paintings are not unanimously acknowledged by scholars to be self-portraits, and in the case of The Entombment of Christ, are completely transformed in the film's re-creation process. In the early section of the film there are a number of art-images that situate the young Caravaggio as the subject, namely Boy with a Basket of Fruit (c1593) and Young Sick Bacchus (c1593). Boy with a Basket of Fruit is the first example of a tableau in the film, formed in a brief daydream from the young artist, and provides the first historically inaccurate example of a self-portrait. This is followed soon after by the example of second painting, Young Sick Bacchus. With the actual canvas displayed in the background, and the sick painter who resembles the figure in the painting in physique, if not in pose, present, Young Sick Bacchus is not staged as a tableau but places the disputed self-portrait as an explicit self-portrait by merging the circumstances of the film and the painting together - the ill, yellowed, painter remarks that the flesh in his painting is so green because he has been ill all summer: "It is true to life."

Wymer discusses the role that promotional photographs, in particular those of David with the Head of Goliath (c1610), played in this subversive imaging of the paintings, which show Jarman's consistent interest in appropriating the paintings to align them with his narrative ideals. There are a number of tableau-like recreations that were photographed by Mike Laye and Gerald Incandela (many of which can be seen in the published script, Derek Jarman's Caravaggio, and in contemporaneous promotional articles), that do not feature in the film, ${ }^{7}$ including an actual tableau of Young Sick Bacchus. The promotional photograph of David with the Head of Goliath correctly places Caravaggio's head as Goliath, replicating the genuine self-portrait, but complicates the original by re-imagining David as the young Caravaggio. This, as Wymer notes, presents a 'literal depiction of a man destroying himself' 
(2005: 107). As well as many sources acknowledging that the original painting was a major influence on Jarman, the photograph is such an effective image it is difficult to understand its exclusion from the film.

The most demonstrative sequence in the film that (re)situates a painting as a self-portrait is the final scene which displays The Entombment of Christ. A small boy, presumably Caravaggio (he is named Michele) and a young man, Pasqualone, watch a solemn Easter procession journey through an empty square. Michele, dressed in the garland of Bacchus and the wings of Cupid from Love Victorious, slowly walks towards a curtained doorway and looks inside. The two characters enter the room, and stand in religious awe at the image presented in front of them: a tableau vivant of The Entombment. The similarity between the art-image and the original painting is striking, with the close-up shots of specific areas of the tableau signifying the attention to detail given to costume, characterisation, pose and lighting. However, there are some subtle differences, such as Christ's body position, which is tilted further towards the viewer than in the artwork, and one major revision, which entirely changes the premise of the painting: the representation of Caravaggio in the position of Christ. By arranging Caravaggio as the crucified figure in the tableau, Jarman is directly suggesting the painter's identification with Jesus, as Bersani and Dutoit posit, 'as if the work had been 'postponed' until its power over its creator could be shown within it' (1999: 45). This revision brings the boy, Michele, face-to-face with his future death, sharing a similarity with the David with the Head of Goliath photograph mentioned above, which perhaps explains the latter's omission. The significance of this full-circling image is left unexplained, but in the words of Bersani and Dutoit, acts as 'a figural metaphor deployed in cinematic time, a metaphor for the multiplication of the artist's identity in the working time of his art' (1999: 46). This assessment, again, points also to Jarman's own identification with the painter, whom he admired so greatly that he felt the need (and had the confidence) to amend his paintings to successfully incorporate them in the Jarman-Caravaggio narrative told in the film.

This confident re-imagining of Caravaggio's artworks recalls Ingeborg Hoesterey's discussion of Jarman as a 'pasticher'; a figure whom adopts, or in some cases, imitates, a variety of past sources into their own work. Hoesterey specifically draws attention to Caravaggio's wild array of anachronisms, from historically inappropriate props (a gold pocket calculator), to unspecific non-diegetic sounds (a motorcycle engine), to contemporary speech (swear words and phrases such as "fucking brilliant"). She claims that this amalgamation of historical and contemporary elements highlights a parallel 'between the circumstances and politics of an artist's life [...] at the turn of the seventeenth century and the eventful bohemian life of today' $(2001: 65)^{8}$ which encourages our contemporary consciousness to reappraise the baroque master. This anachronistic imperative of Caravaggio can also be seen as an attempt to mirror the artist's own inaccurate technique of using contemporary models (the visibly pregnant Lena, for example) and attire in his depiction of historical biblical scenes. Interestingly, Hoesterey also points to the dissolution of painting into cinematic time-flow as pastiche, with the 'painterly film [becoming] a pastiche of the old-masterly art' (2001: 63), exclaiming that Caravaggio provides an excellent example of 
Bazin's exploration of 'Painting and Cinema' - the static art-images literally 'becoming part of that "picturable" world' (Bazin, 2004: 166) that lies beyond the cinema in their relocation as poses for the painter as he works.

\section{Jarman, Greenaway, and editing The Death of the Virgin}

Derek Jarman and another English director, Peter Greenaway, are frequently discussed together as outsider experimental filmmakers from a similar era in British cinema. This academic relationship fostered by scholars perhaps reveals more about the expediencies of writing on British film history than it does about either director (the two are often combined in the token chapter on the 'art film' to prove that Britain had successful avant-garde filmmakers during the 1980s) but interestingly, Greenaway's essay film Rembrandt's J'Accuse (2008) provides a number of points that relate to, and can help us further understand, Jarman's film. ${ }^{9}$ Rembrandt's J'Accuse is a documentary following Greenaway's unravelling of Rembrandt van Rijn's (1606-1669) iconic masterpiece Night Watch (1642). Greenaway attempts to interpret the clues in the painting left behind by Rembrandt that point to a murder and the culprit, and provides an explanation of how this sensational accusation lead to the artist's bankruptcy and disgrace. The film uses the source of the painting as the foundation for this investigation, progressing into social-historical elements, production issues, Rembrandt's biography and dramatic re-enactments of suggested events (taken from Greenaway's companion feature film Nightwatching (2007)).

Firstly, Greenaway examines the "curious significance" of a small collection of Rembrandt paintings on display at the National Gallery, London. Here Self Portrait at the Age of 63 (1669) is hung next to A Woman Bathing in a Stream (1654) - speculated to be a portrait of Rembrandt's mistress, Hendrickje Stoffels - and The Woman Taken in Adultery (1644). His observation notes the intended or accidental connection formed between the three paintings due to their display arrangement, reflecting the biographical history of Rembrandt, and the incident of his mistress, Stoffels, being called to the attention of the Amsterdam church elders for public reprimand for her affair with the painter. This acknowledgment of the relationship formed between neighbouring paintings on display is relevant to Caravaggio in the adoption of this logic on film: the display order of the paintings (not hung, as seen in a gallery or museum, but rather presented on screen) and the relationships that are formed between these recreations, as the papers by Lent and Bazin have formerly distinguished. Greenaway pointedly remarks that the reading may be intended by whoever curated the exhibit. Indeed, in Caravaggio, these relationships are not created by the viewer but are rather dictated by Jarman's construction of the narrative, with one painting leading on to another. Thus, two paintings, which would normally be disparate, are uniformly linked; Lena's Penitent Mary Magdalene (1594-1595) moves successfully into Death of the Virgin, with the same model as two different biblical figures without any concern for historical accuracy. The artworks are removed from their original context and placed within a new narrative path.

Secondly, in his exploration of Night Watch, Greenaway literally takes apart the painting for close analysis - isolating sections via close-up and collage techniques (presenting the highlighted portion in boxes layered on top of the main screen image), segmenting the image 
to accentuate focal aspects. Caravaggio uses a similar method in its art-image sequences, presenting individual close-up shots of selected sections of the tableaux, directing our attention to specific areas of the recreations. This occurs in a number of sequences (the aforementioned The Martyrdom tableau, for example) but is most successful in the later full tableau recreations, in particular that which presents an event with a multitude of characters, such as Death of the Virgin.

Lena has been found murdered at the hands of Ranuccio. To console his grief, Caravaggio decides to create one last painting with Lena as his model. Her body is washed, clothed, and delicately placed on a table, and in the montage that proceeds we are shown close-up segments of the tableau image. Like pieces of a puzzle waiting to be arranged and completed, we see individual images of her pale face with her hair brushed back, her worn feet, and the solemn expressions of the figures positioned around the Virgin, showing varying degrees of sorrow and grief. Finally, we see a shot of Lena's lifeless hand resting on her red cloak (just above her stomach, signifying her pregnancy). Caravaggio places his hand on top of hers for a moment, looks at Lena's peaceful face, and walks away from the image he has created. It is the point at which Caravaggio turns away that the camera unveils the full tableau vivant, cutting from a close-up of his sombre expression to a medium frontal shot of the art-image, where the camera lingers for a while to allow the audience to comprehend this completion of the puzzle.

The intrusive editing of the art-image forces us to pay attention to the aspects of the image that the director deems important. Of course, this is true of cinematic editing in general, but in this case the explicit directing of our gaze disables personal interpretation of the image, further disconnecting the tableau from the original painting and establishing its narrative significance in the film. Thus, in this scene, as I have mentioned, we are explicitly shown through editing, Lena's hand resting on her stomach, recalling the character Lena's pregnancy, and the historical Lena's speculated pregnancy which outraged the church when the commission was presented. Furthermore, the close-ups of the mourning figures surrounding Lena are clearly detailed representations of Caravaggio's own silent grief, with the sequence of shots building up to the close-up of his own despondent face, and the repetition of edits reinforcing the painters delicate emotional state. As the painter gently places his hand on Lena's we can see his emotional investment in this work. This is part of his grieving process: making her forever immortal in paint as the Virgin Mary, the perfect image of womanhood. As James Tweedie has observed,

These tableaux shown on screen exist not as a conduit for the ostensible subject matter of the painting, the narrative announced in titles or museum placards, but instead initiate a speculative recreation of their immediate conditions of production. (2003: 381)

This reading of the art-image is entirely entwined with the narrative of the film by design, and as a consequence it is almost impossible to acquire the same reading of the tableau as you would if you looked at the original painting. ${ }^{10}$ The art-image is presented as part of the fictional artist's process, inspired by the artist's life, and created by the artist in preparation 
for his painting. In addition to this, this close-up detailing effect disturbs the traditional viewing experience of the audience. The viewer is no longer allowed to read the image at his own leisure, uncovering meaning within the painting, but is instead explicitly guided through the image and shown what to look at, literally 'pulling the work apart [and] breaking up its component parts' to reveal 'hidden powers' (Bazin, 2004: 169), or rather hidden interpretations.

\section{Conclusion}

To return once more to Bazin's accusation that the transference of painting to film 'profoundly changes its nature', we can conclude that Jarman's use of the art-image is indeed intrusive upon the original artwork. Fundamentally, these edits explicitly demonstrate to the audience Bersani and Dutoit's 'moving time', visually creating a rhythm in their sequencing which contradicts the art-images' intent interest in recreating the stillness of painting. Additionally, for Bersani and Dutoit the service that film provides, 'briefly relieving us from the burden of using time in order to organize space', deciding what to look at for us by enforcing our 'perceptual passivity' (1999: 50), is a double-edged sword; providing us with all the valuable information, but seizing our perception, ensuring that we are watching at all times in case we miss something. This is only accentuated by the use of edits displaying sections of the image before we can view it in its entirety. We understand that these grieving men and this pale hand have some overall significance, but can't entirely comprehend what this is until the full tableau is revealed. The image is displaced through these edits which in turn can only be understood with the hindsight that the tableau, which has already been narratively displaced from its original source, provides.

Still more important is the impact that this dislocation has on the history and biography of the art and the artist. As the 'edited' art-image sequences and the other historically manipulated paintings testify, in Caravaggio it is Jarman's authorial power which is paramount. Jarman is more concerned with presenting his interpretation of Caravaggio than a factually accurate representation of his life. The lack of verifiable biographical material on his subject benefits this approach. Jarman can build upon the bare minimum - here is a man; a painter, who lived in Italy, during these dates; who painted these paintings; who knew these people; who killed this man - and respectfully extrapolates from other information to introduce his impression of Caravaggio's character and experiences as translated through his art. As Lent observes, the biographical narrative makes it difficult to separate the two elements. Life and art are always intertwined, so why not construct a film around the paintings, especially when that is nearly all that is resolutely known about the subject? But for Jarman even this is not enough. He chooses to directly challenge art-history, mapping a narrative around speculative circumstances. Visually, the tableaux maintain some surface fidelity to the paintings, even recreating the historical layers of process in Caravaggio's work on The Martyrdom of Saint Matthew, but Jarman plays with the characters, mixing history with fiction. Ranuccio becomes Saint Matthew, the jealous murderer, and later the murdered lover. Lena becomes the pregnant lover, the mother-figure of Mary Magdalene, and then the murdered 'Virgin' Mary. Caravaggio becomes the artist, lover, murderer, Christ, and of course, Jarman himself. Everything is filtered through Jarman's interpretation and construction. 
Despite Bazin's assessment that the 'nature' of an artwork is essentially lost when adopted within a different medium it is worth turning to his parting statement and applying it in the service of my own conclusion:

It should therefore be clear, from now on, that the cinema not only far from compromising or destroying the true nature of another art, is, on the contrary, in the process of saving it, of bringing it to general attention. (2004: 168)

As film has the power to bring art to wider audiences, and preserve, duplicate and distribute it in a way that exceeds the ontological structure of painting, so too does the biopic with biographical history. Certain liberties may be taken with aspects of the subject's life and career, certainly this is the case with Caravaggio, but we should celebrate the biopic's ability to present the artist subject and their work to a wider audience, to create an approachable visual narrative of history hidden within museums, archives, and in books and documents.

This article is an edited version of a thesis submitted to the University of Kent, completed with financial support from the AHRC Research Preparation Masters Award (www.ahrc.ac.uk).

${ }^{1}$ This paper draws from very broad concepts of medium-specificity but the subject is by no means the focus of my discussion. For a recent demonstration of the key arguments surrounding this topic, with an emphasis on film, please look to chapter 7, 'The Role of the Medium', of Berys Gaut's A Philosophy of Cinematic Art. ${ }^{2}$ Of course, here it is worth noting Roland Barthes' renowned 'The Death of the Author', published in ImageMusic-Text, which challenges the reasoning that 'the explanation of a work is always sought in the man or woman who produced it' (Original emphasis, 1968 [1977]: 143). Barthes' exploration is specific to the literary author, but commenting that there may be criticism directed towards the view that knowledge of the artist (or poet, or musician) can provide the only rationalisation of his work, his objective is to diminish the authority of the Author and the self-appointed position of the Critic and replace it with the 'birth of the Reader':

We know now that a text is not a line of words releasing a single 'theological' meaning (the 'message' of the Author-God) but a multi-dimensional space in which a variety of writings, none of them original, blend and clash. The text is a tissue of quotations drawn from the innumerable centres of culture (146).

Clearly, from Lent's assessment, the genre of biography and its focus on the artist's life as an explanation for the art pays little concern to Barthes' long-established argument.

${ }^{3}$ Lent draws attention to Taymor's decision to use Frida and Diego Rivera (1931) as a direct representation of their wedding despite the known historical inaccuracy and the existence of wedding photographs that show Kahlo wearing a different bridal outfit. Lent also highlights Taymor's use of My Dress Hangs There (1933) as a speculative literalisation of Kahlo's wish to return to her home in Mexico.

${ }^{4}$ Paintings are actually shown in Caravaggio, either as works in progress or as completed products (such as Amor Vincit Omnia [Love Victorious] (1601-1602)). However, these paintings are not the original artists own (even the completed Caravaggio paintings are replicas) and this appropriation is not the focus of this study. ${ }^{5}$ Obviously, Bazin had no knowledge of future advancements, but the expansion of the use of modern digital technologies confuses this assumption. For example, the creation of purely digital images seen in digital animation and special effects which have no concrete existence within our reality present a variety of scholarly challenges.

${ }^{6}$ In fact it is widely understood that Ranuccio Tomassoni was killed following a dispute over a tennis match.

${ }^{7}$ Many of the images I have seen are drawn from Jarman's own press cuttings from box 7 of his unpublished diaries at the Special Collections department, BFI National Library, London. Accessed 07/03/12. 


\footnotetext{
${ }^{8}$ John A. Walker makes a similar statement speculating the similarities between Jarman and Caravaggio's gay, potentially avant-garde ('anti-authority' at the very least) lifestyle (1993: 60).

${ }^{9}$ The BFI DVD release of Caravaggio (R2 DVD. BFI, 2007) compellingly fuels this comparison further with its menu design evoking Greenaway's techniques of visual layering and the use of multiple text and image boxes presenting various layers of information. Also, as a further point, Hoesterey's chapter on 'Cinematic Pastiche' (cited above) provides an excellent insight of how Jarman and Greenaway can, with consideration, occasionally act as valuable side-by-side examples.

${ }^{10}$ What this original reading would be, of course, is not known. It certainly wouldn't involve this empathic resonance with Caravaggio and concern for the painter and model's relationship, because, naturally, this fictional construction is nothing to do with the artwork itself.
}

\section{References}

Barthes, Roland. (1968 [1977]) 'The Death of the Author,' Image-Music-Text. London: Fontana Press, pp.142-148

Bazin, André. (Original date unknown [2004]) 'Painting and Cinema,' What is Cinema?: Volume 1. Berkeley: Univ. of California Press, pp.164-169

Bersani, Leo, and Dutoit, Ulysse. (1999) Caravaggio. London: BFI Publishing Gaut, Berys. (2010) 'The Role of the Medium,' A Philosophy of Cinematic Art. Cambridge: Cambridge Univ. Press, pp.282-307

Hoesterey, Ingeborg. (2001) 'Cinematic Pastiche,' Pastiche: Cultural Memory in Art, Film, Literature. Bloomington, IN: Indiana Univ. Press, pp.45-79

Jarman, Derek. (1984) Dancing Ledge. London: Quartet Books

-----. (1986) Derek Jarman's Caravaggio: The Complete Film Script and Commentaries. London: Thames and Hudson

------. Unpublished diary \& script collection. 'Derek Jarman II,' Boxes 6-11. Available at the Special Collections Department, BFI National Library, London. Accessed $07 / 03 / 12$

Lent, Tina Olsin. (2007) 'Life as Art/Art as Life: Dramatizing the Life and Work of Frida Kahlo,' Journal of Popular Film \& Television. 35:2, Summer, pp.68-76

Tweedie, James. (2003) 'The Suspended Spectacle of History: The Tableau Vivant in Derek Jarman's Caravaggio,' Screen. 44:4, Winter, pp.379-403

Walker, John A. (1993) Art and Artists on Screen. Manchester: Manchester Univ. Press

Wymer, Rowland. (2005) 'Red is Just Blue Screaming': Caravaggio (1986),' Derek Jarman. Manchester: Manchester Univ. Press, pp.92-109 